\title{
Sacroiliitis after use of oral isotretinoin - association with acne fulminans or adverse effect?
}

\author{
Sacroileíte após uso de isotretinoína oral - associação com acne fulminans \\ ou efeito adverso?
}

\author{
Ariane Silva Bastos Geller ${ }^{1}$
}

Roberta Ferreira Nazareth Alagia²

DOI: $h$ ttp://dx.doi.org/10.1590/abd1806-4841.20132500

\begin{abstract}
Acne fulminans is a rare and severe form of acne that may evolve from acne vulgaris, especially in male adolescents, or occur as an adverse effect of oral isotretinoin. Arthritis is a serious clinical manifestation when the musculoskeletal system is compromised by AF and has been reported as a rare adverse effect of isotretinoin. Involvement of the sacroiliac joints occurs in $21 \%$ of acne fulminans cases. We present the case of a 18 -year-old male patient in whom acne fulminans evolved from acne vulgaris grade IV and after inflammation resolution started treatment with oral isotretinoin. Within a 30-day period of retinoid treatment he presented with back pain followed by rapid, progressive inability to deambulate.
\end{abstract}

Keywords: Acne vulgaris; Arthritis; Isotretinoin; Sacroiliitis

Resumo: Acne fulminans é uma forma grave e rara de acne que pode ser evolução da acne vulgar, principalmente em adolescentes do sexo masculino, ou ser precipitada durante o tratamento com isotretinoína oral. A artrite pode ocorrer como grave complicação na acne fulminans e já foi relatada como efeito adverso raro da isotretinoína. $\mathrm{O}$ acometimento das articulações sacroilíacas ocorre em $21 \%$ das artrites associadas à acne fulminans. Relatase caso de paciente masculino, 18 anos, que desenvolveu acne fulminans a partir de acne vulgar grau IV/conglobata e após resolução do quadro inflamatório, foi iniciado tratamento da acne com isotretinoína. Com 30 dias de uso do retinóide, o paciente iniciou dor lombar com piora rápida, progressiva que o incapacitou de deambular. Palavras-chave: Acne vulgar; Artrite; Isotretinoína; Sacroileíte

\section{INTRODUCTION}

Isotretinoin is a safe and effective drug that has been used for over thirty years in the treatment of acne. The more frequent adverse effects are related to skin and mucous membranes. ${ }^{1}$ Arthralgias, and more rarely sacroiliitis and polyneuropathy, signal musculoskeletal system involvement. ${ }^{2}$

Likewise, the acne fulminans (AF) described by Plewig and Kligman in 1975 is characterized by sudden onset of ulcerous/crusted acne and systemic symptoms, including fever and weight loss, osteoarticular signs and laboratory tests alterations. It can also be triggered by isotretinoin and has sacroiliitis as a clinical manifestation. . $^{1,2,3}$ This is the report of a case of an adolescent who developed acne fulminans from grade IV acne vulgaris, and after resolution of the inflammatory process, while initiating treatment with oral isotretinoin, presented with bilateral sacroiliitis after 30 days of treatment. The association of the retinoid with the clinical picture developed is discussed in this report .

\section{CASE REPORT}

An 18-year-old male patient had the onset of acne 3 years ago, with worsening in the 40 days that preceded the examination at the outpatient clinic. He presented fever and arthralgias for 7 days, more intense on the sternal region and left shoulder, associated with pustules and confluent nodules which formed crusted erythematous plaques in the malar region, with formation of fistulous tracts in the bilateral mandibular region, extending to the preauricular area with purulent secretion (Figure 1). However, there were no thorax nor dorsum lesions. Laboratory exams showed leucocytosis $22,640 / \mathrm{mm}^{3}$ with $78.8 \%$ neutrophils, without hepatic or lipid profile alterations.

Received on 30.01.2013.

Approved by the Advisory Board and accepted for publication on 17.03.2013.

Work performed at Dermatology and Venereology Foundation Alfredo da Matta (FUAM) - Manaus (AM), Brazil.

Conflict of interest: None

Financial Support: None

MD, PhD program student - Resident at Fundação de Dermatologia e Venereologia Alfredo da Matta (FUAM) - Manaus (AM), Brazil

MD, residence in Dermatology - Dermatologist at Fundação de Dermatologia e Venereologia Alfredo da Matta (FUAM) - Manaus (AM), Brazil. 
The drugs in use (topic betamethasone, gentamicin and benzoyl peroxide) were suspended and dapsone $100 \mathrm{mg} /$ day and minocycline $100 \mathrm{mg}$ / day prescribed for 21 days. With the clinical improvement and normalization of the hemogram, oral isotretinoin, $40 \mathrm{mg} /$ day $(0.67 \mathrm{mg} / \mathrm{Kg} /$ day) was prescribed. After 30 days there was significant improvement of cutaneous lesions, with pustules more concentrated on the perioral region, in addition to papules and erythema in the malar and mandibular region, which already showed healing of the fistulous tracts (Figure 2). At the same time, the patient reported intense lumbar pain of quick progression, which prevented ambulation, resulting in hospitalization, suspension of isotretinoin and use of analgesics and non-steroidal anti-inflammatory. The lumbar spine radiography and MRI, performed during hospitalization, did not show alterations that could explain the clinical condition. After hospital discharge, the patient returned to the outpatient clinic using a wheelchair, and an orthopedic evaluation was requested. The non-steroidal anti-inflammatory was continued and a bone scintigraphy was requested. Bone scintigraphy, done after hospitalization, when the patient was already walking with the aid of crutches, detected the radiopharmaceutical trapped in the sacroiliac articulations, which was conclusive for light bilateral sacroiliitis (Figure 3). The HLA-B27 antigen was negative. The patient maintained improvement of the articular condition, with progressive recovery of ambulation after the use of orthesis and physical therapy. The acne condition presented excellent results with the use of oral isotretinoin for 30 days and after its suspension, benzoyl peroxide $5 \%$ associated with adapalene $0.1 \%$ and intermittent oral antibiotic therapy, showing few inflammatory lesions and residual erythema (Figure 4).

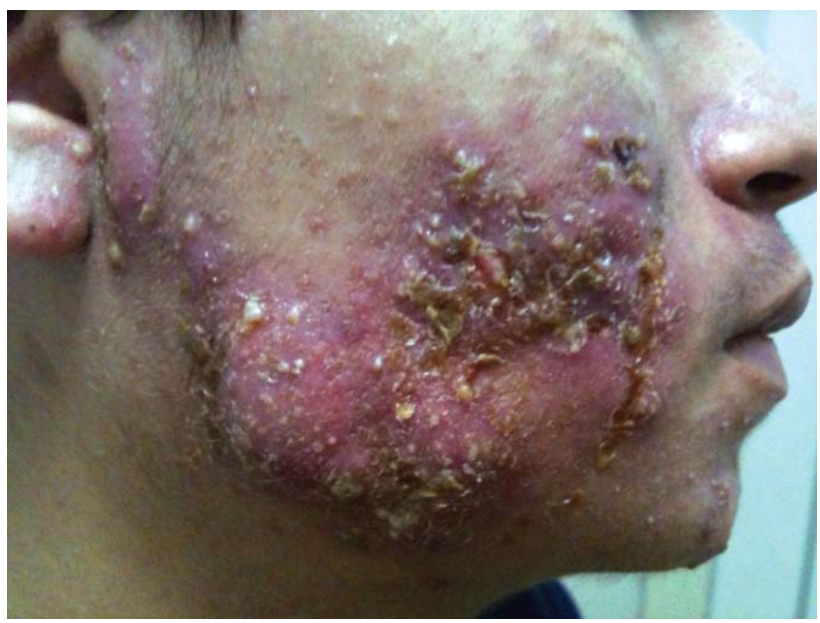

Figure 1: Presence of pustules, nodules and crusts on face, predominantly in the malar region
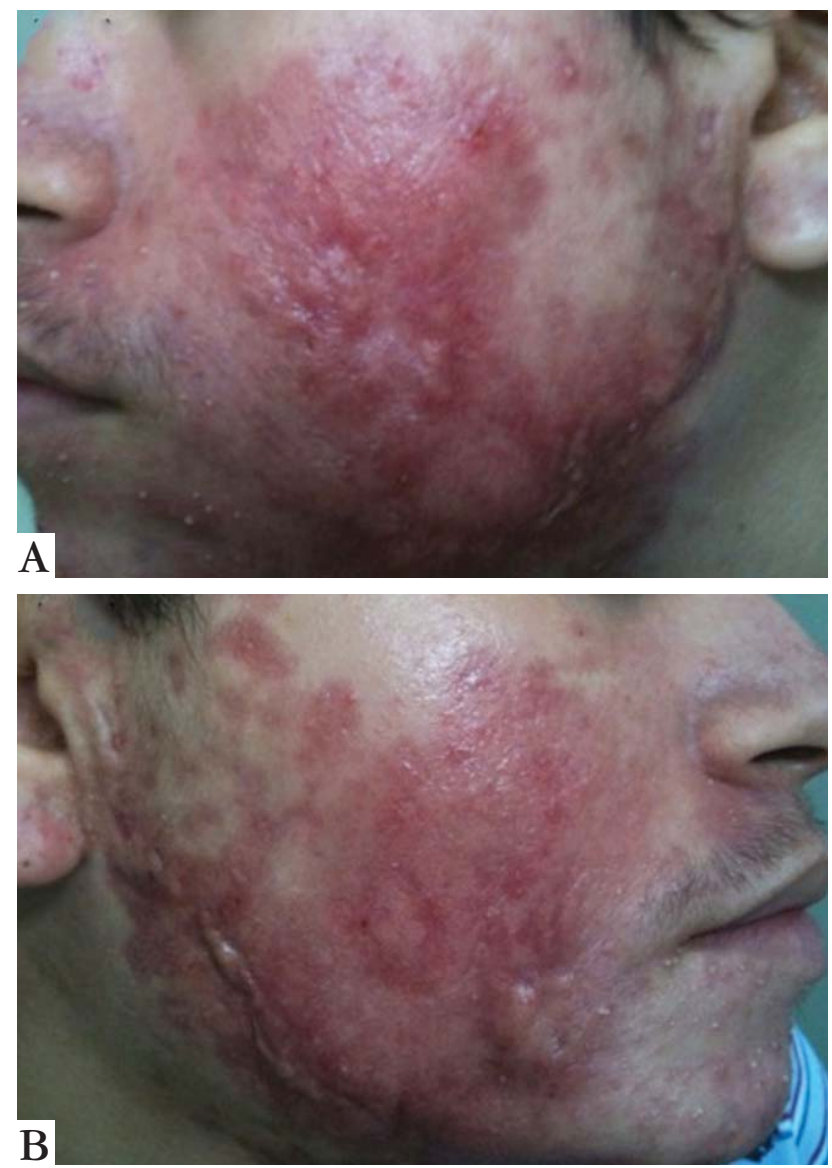

FIGURE 2: Improvement of condition 30 days after use of oral isotretinoin. A) presence of pustules, erythema and papules; B) Pustules, erythema and fistulous tract

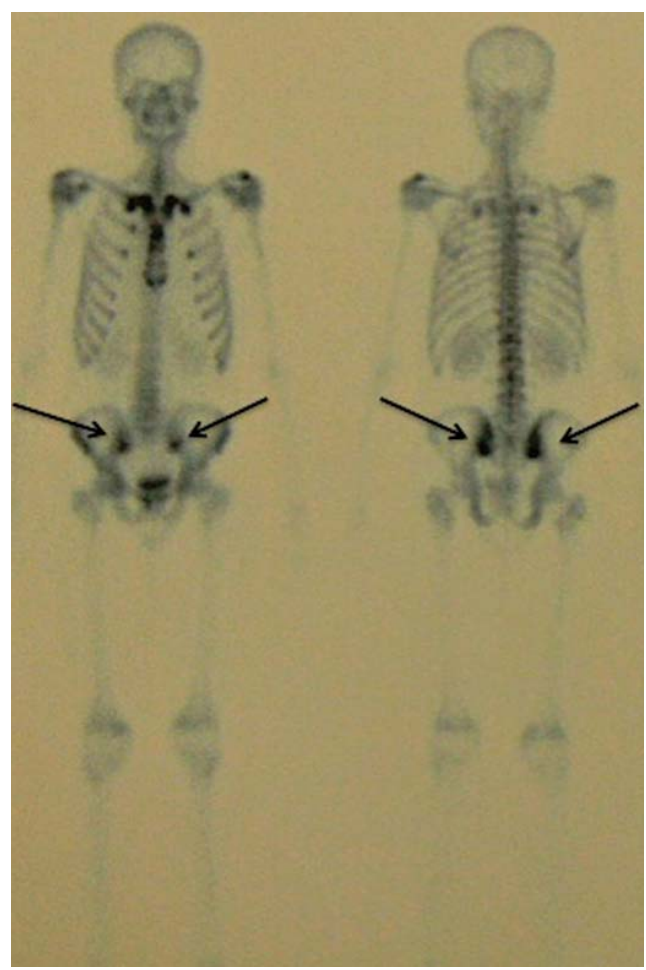

FIGURE 3:

Bone scintigraphy showing light bilateral sacroiliitis (arrows) 

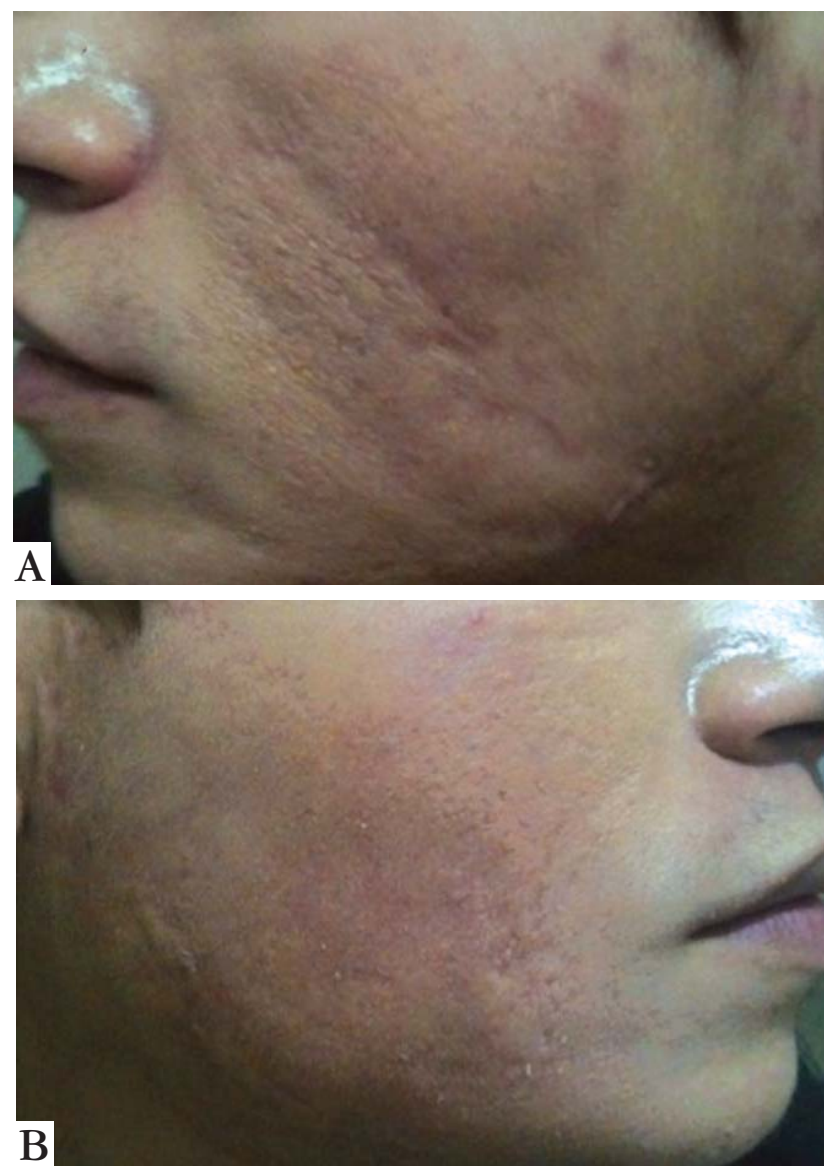

FIGURE 4: Patient under maintenance acne treatment with improvement of clinical condition. A e B: presence of multiple scars

\section{DISCUSSION}

Acne vulgaris, in all its clinical variables, involves $80 \%$ of young people and has in acne fulminans, which affects $1 \%$ of this population, its most severe form. It predominates in men between 13 and 22 years of age and is characterized by abscesses, crusted hemorrhagic ulcerative lesions and purulent areas that invariably involve the trunk with less intense facial involvement, associated with sudden systemic manifestations like high fever, weight loss, asthenia, adenopathies and osteoarticular involvement that affects mainly big articulations. ${ }^{4,5}$ Clinically, it differs from grade IV or conglobata acne, for even of the latter presents nodule-cystical eruptive lesions, there is no systemic symptomatology. Laboratory exams show that with acne fulminans there is evident leuco- cytosis, with left deviation and increased erythrocyte sedimentation speed. ${ }^{4}$ Despite the absence of extrafacial involvement in the reported patient, the presence of signs and systemic symptoms of sudden onset accompanied by expressive leucocytosis, besides the worsening and characteristics of the facial cutaneous lesions, supported the diagnosis of acne fulminans.

As previously mentioned, acne fulminans can involve the musculoskeletal system and more commonly causes bone pain, arthralgias and arthritis. When accompanied by arthritis, the sacroiliac articulations are involved in $21 \%$ of the cases reported on the literature. ${ }^{5,6}$ There are reports of acne fulminans caused by isotretinoin, however in none of them it is related to the antigen HLA-B27.,8

Oral isotretinoin is a drug largely employed in dermatology. This oral retinoid is indicated for the treatment of grade III/nodular acne and grade $\mathrm{IV} /$ conglobata or fulminans and presents as the most common adverse effect drying of skin and mucous membranes. ${ }^{1}$ Rare situations like polyneuropathy and seronegative sacroiliitis can occur, as in the described case. $^{2,7,8}$ As a pathogenic mechanism, it was suggested that isotretinoin could induce solubilization of the liposomal membrane and consequently cytopathic destruction of the synovium, causing arthritis as an adverse effect. ${ }^{9}$ Ekisioglu and others (2007) suggested that the positivity of antigen HLA-B27 renders the patient susceptible to the development of sacroiliitis; however, the other cases described in the literature do not corroborate this statement. ${ }^{78,10}$

In the case presented, bilateral sacroiliitis occurred only after the introduction of oral isotretinoin, when the acne fulminans condition was resolved, with normalized hemogram and clinical absence of inflammation. Based on the chronology of events and expressive improvement of arthritis after suspension of oral isotretinoin, in the described case the sacroiliitis was associated with the retinoid. However, it is known that this type of clinical manifestation can occur late when associated with acne fulminans and it is not possible to exclude this possibility. Whatever the case, the investigation of rheumatological associations and careful follow-up of patients that show osteoarticular involvement are indispensable, especially in sacroiliitis, an arthritis that involves the axial skeleton and is thus considered severe. $\square$ 


\section{REFERENCES}

1. Montagner S, Costa A. Diretrizes modernas no tratamento da acne vulgar: abordagem inicial à manutenção dos benefícios clínicos. Surg Cosmet Dermatol. 2010;2:205-13.

2. Eksioglu E, Oztekin F, Unlu E, Cakci A, Keyik B, Karadavut IK. Sacroiliitis and polyneuropathy during isotretinoin treatment. Clin Exp Dermatol. 2007;33:122-4.

3. Plewig G, Kligman AM. Acne: Morphogenesis and treatment. Berlin: Springer; 1975. p.196.

4. Romiti R, Jansen T, Plewig G. Acne fulminans. An Bras Dermatol. 2000;75:611-7.

5. Zanelato TP, Gontijo GM, Alves CA, Pinto JC, Cunha PR. Acne fulminans incapacitante. An Bras Dermatol. 2011;86:S9-12.

6. Knitzer RH, Needleman BW. Musculoskeletal syndromes associated with acne. Semin Arthritis Rheum. 1991;20:247-55.

7. Bachmeyer C, Charoud A, Turc Y, Callot V, Blum L, Aractingi S. Isotretinoin-induced bilateral sacroiliitis. Dermatology. 2003;206:285-6

8. Barbareschi M, Paresce E, Chiaratti A, Ferla Lodigiani A, Clerici G, Greppi F. Unilateral sacroiliitis associated with systemic isotretinoin treatment. Int $\mathrm{J}$ Dermatol. 2010;49:331-3.

9. De Francesco V, Stinco G, Campanella M. Acute arthritis during isotretinoin treatment for acne conglobata. Dermatology. 1997:194-5.

10. Rozin AP, Kagna 0, Shiller Y. Sacroiliitis and severe disability due to isotretinoin therapy. Rheumatol Int. 2010;30:985-6.
MAILING ADDRESS:

Ariane Silva Bastos Geller

Av Codajás, 24 - Cachoeirinha

69.065-130 - Manaus - AM

Brazil

E-mail: arianegeller@hotmail.com

How to cite this article: Geller ASB, Alagia RFN. Sacroiliitis after use of oral isotretinoin - association with acne fulminans or adverse effect? An Bras Dermatol. 2013;88(6 Suppl 1):S193-6. 